\title{
Ultra-Wideband Radar for Breath Tracking with Optical Fiber for Remote Reach Extension
}

Suhr, Lau Frejstrup; Tafur Monroy, Idelfonso ; Vegas Olmos, Juan José

Published in:

Proceedings of Optical Fiber Communications 2016

Link to article, DOI:

10.1364/OFC.2016.Th2A.27

Publication date:

2016

Document Version

Peer reviewed version

Link back to DTU Orbit

Citation (APA):

Suhr, L. F., Tafur Monroy, I., \& Vegas Olmos, J. J. (2016). Ultra-Wideband Radar for Breath Tracking with Optical Fiber for Remote Reach Extension. In Proceedings of Optical Fiber Communications 2016 https://doi.org/10.1364/OFC.2016.Th2A.27

\section{General rights}

Copyright and moral rights for the publications made accessible in the public portal are retained by the authors and/or other copyright owners and it is a condition of accessing publications that users recognise and abide by the legal requirements associated with these rights.

- Users may download and print one copy of any publication from the public portal for the purpose of private study or research.

- You may not further distribute the material or use it for any profit-making activity or commercial gain

- You may freely distribute the URL identifying the publication in the public portal 


\title{
Ultra-Wideband Radar for Breath Tracking with Optical Fiber for Remote Reach Extension
}

\author{
L. Frejstrup*, I. Tafur Monroy, J.J. Vegas Olmos \\ Technical University of Denmark, Department of Photonics Engineering, Ørsted Plads 343, Kgs. Lyngby, Denmark \\ *lasu@fotonik.dtu.dk
}

\begin{abstract}
We report on the experimental demonstration of an UWB radar with fiber extension for remote breath tracking through $10 \mathrm{~cm}$ of concrete. The radar is based on telecom class equipment.
\end{abstract}

OCIS codes: (280.5600) Radar, (060.2310) Fiber optics, (060.2370) Fiber optics sensors, (350.4010) Microwaves

\section{Introduction}

Localizing promtly and precisley as possible trapped victims in calamity scenarios casued by earthquakes, accidents, lanslides, snow avalanches or explosions, will increase dramatically the possibilty of saving lives and reducing therefore the number of victims in such disaster zones. It also of most relevance to have such localizing tools and technologies user friendly and at easy disposable of rescue workers.

Ultra-wide bandwidth (UWB) has been extensively investigated as an enabling technology for high speed wireless communications with low emission power [1]; as UWB spreads the information over a wide portion of the radio spectrum, it is also highly compatible with other wireless technologies. UWB is a suitable technology in distributed antenna systems (DAS), where large amount of broadband Wi-Fi antennas are deployed to provide coverage to highly dense indoor areas, as it allows to increase the overall system capacity by having multiple technologies working in liaison to provide connectivity. UWB has some particularities that makes it appealing in non-telecom applications, such as sensing: UWB signals can pass through obstacles, immunity against multipath interference, resolution and low radiation emission (which is key when dealing with life organism).

Because of these advantages, the use of UWB radar systems in rescue scenarios after landslides or building collapses, have been proposed in the past [2-5]. However, these demonstrations assume the transmitter and receiver units are next to the sensing antennas, which infringe a challenge in terms of cost. Ideally, UWB radar signals should be distributed through existing DAS fiber deployments, maintaining the transmitter, receiver and processing units centralized. Therefore, DAS fiber is ideal for static deployment in areas such as the mining industry and health care premises.

In this paper, we propose a reach extender for UWB radar with breath tracking resolution class through optical fiber. Our experimental results effectively demonstrate that UWB signals can be locally generated and processed, while distributed by fiber to distances over several kilometers to a control center. The proposed system has a resolution capable of tracking breathing in a human and the pattern of a Newton cradle, highlighting the resolution of UWB systems.

\section{UWB Radar}

The standard operation of an UWB radar is that the radar emits a pulse and then records when the pulse is returned by the desired target or other objects in the vicinity of the target. These pulses are emitted in time intervals called the repetition rate. A high repeatition rate means that higher frequencies can be recovered in the receiver or that multiple received pulses can be averaged to suppress noise. After choosing an adequate repetition rate, the receiver performs the operation given in $C_{n}=\max \left(R_{n} * R_{n-1}\right)$, where $C$ is the resulting convolution array, $R$ is the received pulse at time $n$. Taking the fourrier transform of $C$ then gives the movement spectrum of the target. Both breathing and heartbeats results in movements and thus, if the utilized pulse is sufficiently short in time, it is possible to recover the breathing or pulse rate of the target. This paper will focus on breathing as pulse recovery has been demonstrated by the use of UWB radars previoulsy. Breathing gives contractions of the thorax in the range of $0.2-0.5 \mathrm{~Hz}$ and therefore the minimum repetition rate of the radar is above $1 \mathrm{~Hz}$ in order to recover this frequency range. 

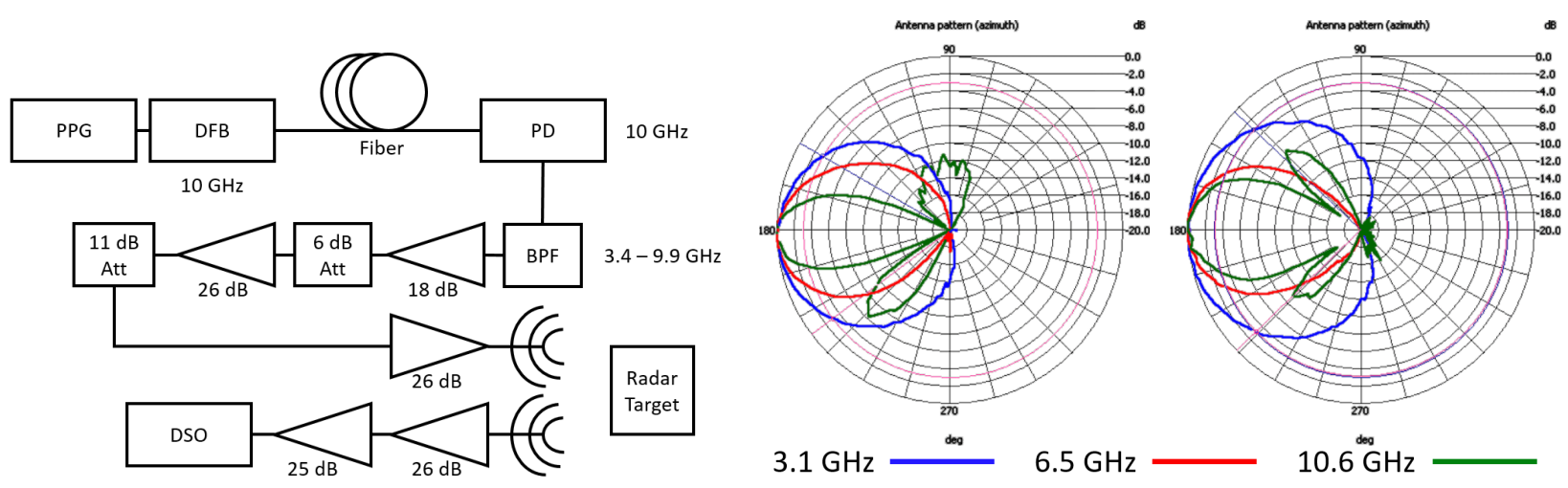

Fig. 1: Left: The experimental setup. DFB: distributed feedback laser, PD: photodiode, DSO: digital sampling scope. Right: The radiation pattern of the antennas used in the experiment.

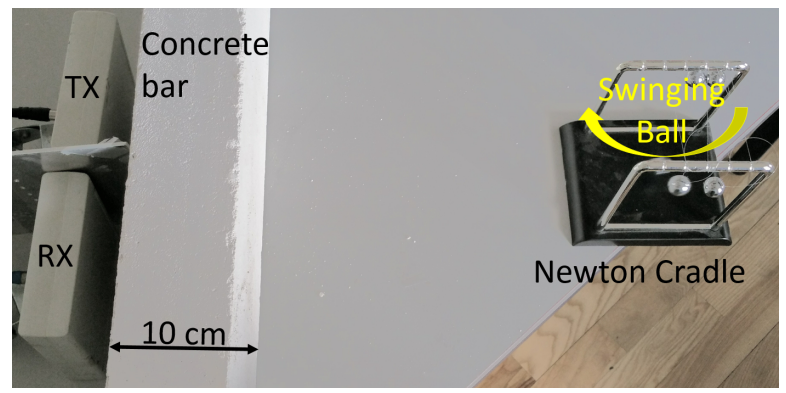

Fig. 2: The concrete bar used as obstacle and the newton cradle used to verify the spectral resolution.

\section{Experimental Setup}

The setup used in the experiment is shown in the left hand side of Figure 1. A telecom grade PPG is used to generate square pulses with $2 \mathrm{~V}$ ptp. This pulse is then transmitted by a $10 \mathrm{GHz}$ Distributed Feedback Laser. After $20 \mathrm{~km}$ Nonzero Dispertion Shifted Fiber (NZ-DSF) the light is received by a $10 \mathrm{GHz}$ Photo Diode (PD). After the PD a Band Pass Filter (BPF) is used to filter out the frequenties that are outside the UWB 3.4-9.9 GHz range. Three amplifiers and two attenuators are used to match the saturation power of the last amplifier which is $26 \mathrm{dBm}$. The pulse is then transmitted and received by $6 \mathrm{dBi}$ gain antennas. After the receiver antenna two amplifiers are used before the data is recorded by a telecom grade Digital Storage Oscilloscope (DSO). The sampling frequency of the DSO was set to 20 $\mathrm{Gsa} / \mathrm{s}$ in order to recover the entire spectrum of the transmitted pulses. The DSO recorded 20 samples per second in order to recover frequencies up to $10 \mathrm{~Hz}$. The right hand side of Figure 1 shows the emission pattern of the antennas used. As can be seen they have a quite broad emission pattern.

In order to verify that the radar can recover the movement spectrum correctly and through concrete, the concerete obstacle and newtown cradle shown in Figure 2 was added. The swing period of the pendulum in the newton cradle is 0.6-0.7 seconds, giving a frequency of $1.6 \mathrm{~Hz}$.

\section{Results}

The measured spectral resolution results of the implemented UWB radar are given in Figure 3. On the left side is the result for recording the Newton Cradle. As can be seen, there is a very clear peak at $1.6 \mathrm{~Hz}$ which shows that the frequency output of the radar is correct and as expected. However, as the newton cradle uses metal balls and that the swing period is very stable it is expected that the cradle will give much better results than any human target.

In Figure 3, the middle plot shows the recovered spectrum of a human breathing on the other side of the concrete bar. A clear peak is visible in the $0.2-0.5 \mathrm{~Hz}$ range. As expected the peak is broader than that of the cradle, as human breathing frequency changes. 

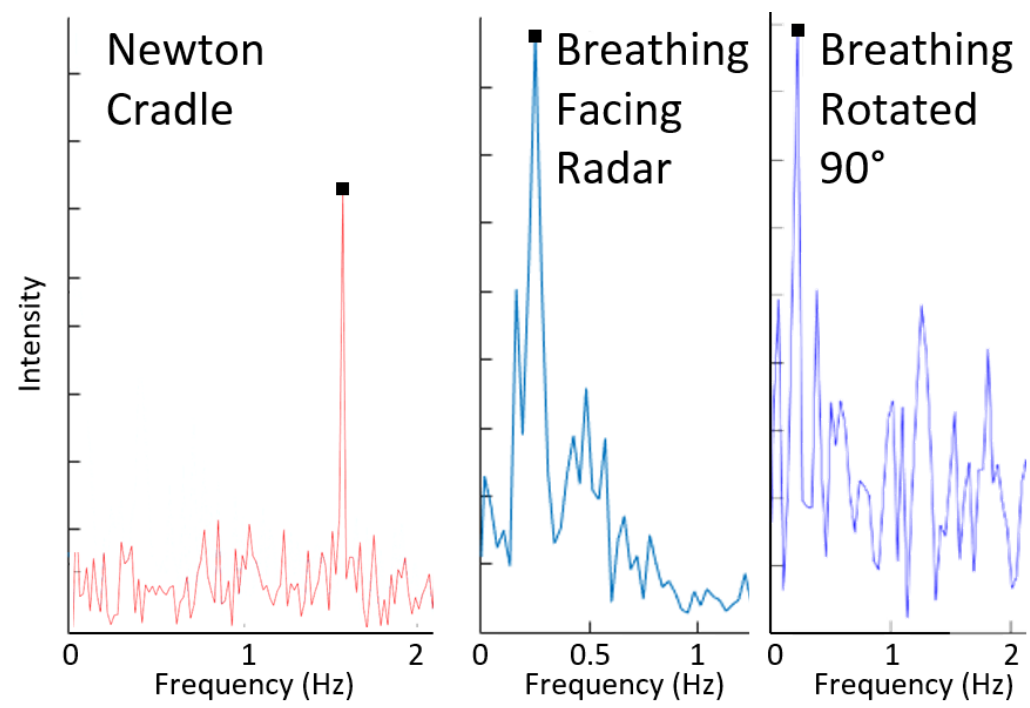

Fig. 3: Measured spectral results of the UWB radar. On the left side the frequency of the newton cradle is recovered, in the middle the breathing frequency of a human, and on the left the breathing frequency of a human facing 90 degrees away from the radar. All three results penetrate a $10 \mathrm{~cm}$ thick concrete bar

The left side plot in Figure 3 shows the recovered spectrum of a human breathing on the other side of the concrete bar. The difference now is that the human is rotated 90 degrees away from the antenna. As it can be seen, the resulting peak in the $0.2-0.5 \mathrm{~Hz}$ range is now much closer to the noise threshold. This is because the breathing movement is not as pronounced from the side as it is from the front. Another feature is that the system employs antennas with a broad emission pattern allowing for recovering breathing frequency with some tolerance for angle misalignment.

\section{Conclusion}

A UWB radar with a $20 \mathrm{~km}$ NZ-DSF reach extension on the transmitter side was experimentally demonstrated. The spectral resolution was verified by using the known swing period of a newton cradle. The implemented UWB radar was able to succesful recover the breathing rate of human targets through a $10 \mathrm{~cm}$ thick concrete bar. The proposed sysems has the prospect to be overlayed over deployed optical fiber infractructures.

\section{Acknowledgement}

This work was supported by the Villums Fonden through the Young Investigator Program SEES project.

\section{References}

1. J. J. Bevensee, R. R. Lopez, M. Beltran, I. T. Monroy "Shared Medium 2 Gbps Baseband \& 2 Gbps UWB In-Building Converged Optical/Wireless Network with Multimode Fiber and Wireless Transmission", ECOC, We.7.B.4, 2010.

2. I. Arai, "Survivor search radar system for persons trapped under earthquake rubble" in Proceedings of AsiaPacific Microwave Conference, Taiwan, 2001, Vol. 2, pp. 663-668.

3. C. Labarthe, J. Mutzig, B. Jecko, H. Hamieh, E. Martinood, N. Feix, M. Lalande, J. Denoual, J. Floch, V. Bertrand, et. al., "An ultra-wideband radar concept for the detection of buried victims beneath building rubble" in Proceedings of the International Radar Conference? Surveillance for a Safer World, Bordeaux, France, 2009, pp. 1-6.

4. J. Li, Z. Zeng, J. Sung, F. Liu, 'Through-wall detection of human being?s movement by UWB radar", IEEE Geosci. Remote Sens. Lett. 2012, 9, pp. 1079-1083.

5. G. Grazzini, M. Pieraccini, F. Parrini, A. Spinetti, G. Macaluso, D. Dei, C. Atzeni, "An ultra-wideband highdynamic range GPR for detecting buried people after collapse of buildings", in Proceedings of the 13th International Conference on Ground Penetrating Radar, Lecce, Italy, 2010, pp. 1-6. 